\title{
Irrigated agriculture in an era of high energy prices
}

\author{
K. Schoengold ${ }^{1}$, T. Sproul $^{2}$ \& D. Zilberman ${ }^{3}$ \\ ${ }^{I}$ Department of Agricultural Economics, University of Nebraska-Lincoln, \\ USA \\ ${ }^{2}$ Department of Agricultural and Resource Economics, \\ University of California-Berkeley, USA \\ ${ }^{3}$ Department of Agricultural and Resource Economics, \\ University of California-Berkeley and the Giannini Foundation, USA
}

\begin{abstract}
Rising energy prices will alter water allocation and distribution. Water extraction and conveyance will become more costly and demand for hydroelectric power will grow. The higher cost of energy will substantially increase the cost of groundwater, whereas increasing demand for hydroelectric power may reduce the price and increase supply of surface water. High energy prices and geopolitical considerations drive investment in land- and water-intensive biofuel technology, diverting land and water supplies to energy production at the expense of food production. Thus, rising energy prices will alter the allocation of water, increase the price of food and may have negative distributional effects. The impact of rising energy prices and the introduction of biofuels can be partly offset by the development and adoption of new technologies, including biotechnology. The models considered here can be used to determine the effects of rising energy prices on inputs, outputs, allocation decisions and impact on distribution.
\end{abstract}

Keywords: Biofuels, conveyance, groundwater, surface water, water price.

\section{Introduction}

At the outset of the $21^{\text {st }}$ century, concern about global climate change seems likely to constrain the massive use of fossil fuels that characterized the preceding century. The $1900 \mathrm{~s}$ witnessed significant human population growth and 
increasing agricultural production, irrigation and energy use. It was a century of significant fossil fuel extraction that heralded the introduction of alternative forms of energy, such as nuclear power. The declining price of energy was crucial for growth and the development of technologies. Now, rapid economic growth in China and India are spurring rising energy demand. Energy prices are much higher than they were at the start of the millennium and are expected to remain above historical levels. These trends suggest the energy paradigm of the last century will need to adapt to the challenges of this century.

The increased cost of energy will impact water systems because of their reliance on energy. In many cases, water demand growth has been facilitated by energy-intensive systems. This paper discusses how increasing energy prices affect water systems, and, conversely, how water affects energy systems. Hydroelectric power, for instance, has been an important source of energy for millennia. New energy sources are emerging in the form of biofuels, which require water in production. We will consider the impact of the introduction of biofuels on water and on other agricultural outputs, including food.

The present paper proceeds with a short overview of the potential impacts of higher energy prices on agriculture. We will assess the impact of increased energy prices on the price of water, food, and other resources, and on the wellbeing of different water users and the end consumer. Then we will assess the impact of higher water prices on policies and institutes governing water use. Finally, we will consider how the introduction of biofuels will affect the water situation, the price of food, and the well-being of consumers and producers.

\section{Overview of the potential impacts of higher energy prices on agriculture}

Because more than 60 percent of water is used in agriculture, we will analyze the impact of high energy prices mostly on agricultural systems, and the benefits we consider are agricultural benefits defined as agricultural revenue. We also consider situations in which water first generates hydroelectric power and then provides agricultural benefits. The benefits of water in such situations are the sum of hydroelectric and agricultural benefits. The demand curve for water depicts the willingness of buyers to pay for an additional unit of water; the willingness to pay is equal to the marginal benefits of water, and thus represents the incremental benefits of water in agriculture and hydroelectric use. Water use entails several cost categories, and our analysis accounts for extraction and transfer costs. In some cases, it also includes the environmental costs associated with diversion of water to production from natural systems and the future costs associated with current use of water that affects water availability in the future. Supply curves depict the amount sellers require to produce an additional unit of the good. In our case, if the seller is extracting water, the supply curve is equal to the marginal extraction costs at a level associated with positive profits.

Energy and fuels are critical inputs for agriculture. Fuels are direct inputs used with farm machinery and beyond the farm gate, both upstream, by input suppliers, and downstream, by processors and marketers. Higher energy prices 
will raise the cost of production, thus reducing agricultural supplies and producing higher prices for agricultural outputs. We will denote this effect as the food price effect, though it also applies to agricultural outputs. Higher food prices may not translate to higher prices at the farm gate because the transportation cost effect will tend to reduce the price received by farmers. Higher transportation costs may cause farm production to locate closer to market and may reduce trade. Higher energy prices have a third effect on resource allocation in agricultural production, which we call the other inputs effect. It embodies the impacts of higher energy prices on the prices and use of agricultural inputs other than water. For example, with higher energy prices, fertilizers and pesticides may become more expensive, and their use may decline. Also, the amount of land used in production is subject to change.

\section{The impacts of higher energy prices on water systems without conveyance}

In a simple water system, water is used near the extraction site. The optimal water use is determined by the condition that the marginal benefit of water is equal to the marginal extraction cost of water (assuming there are no externalities or dynamics). This establishes the optimal price of water. Both marginal benefits and extraction cost depend on the price of energy. The marginal extraction cost is equal to the incremental energy required for extracting an additional unit of water times the price of energy. Therefore, the marginal extraction cost grows proportionately with the price of energy. The marginal benefit of water is equal to the price of output produced by water times the marginal productivity of water in production. Since we consider water systems that are small relative to the output market, farmers are price takers and unable to influence the output price. Thus, a higher energy price will affect the marginal benefit of water in the short run mostly through its impact on the price of output. Consequently, the direction of the shift in the marginal benefit after an increase in energy prices depends on the relative strength of the food price effect and the transportation effect. In some locations far from markets, transportation costs dominate, but in most locations, the food price effect will dominate.

We can analyze how an increase in energy prices will affect water use and the optimal water price for a region that starts with traditional irrigation and extraction technologies. The likely outcome of higher energy prices is to increase water price and reduce water use, but impacts vary among regions. In regions where farmers produce for the local market only (the region is an importer of food) and have relatively low transportation costs for their products, the increase in the price of water will be larger and the reduction in water use smaller than in regions where farmers primarily produce for a more distant export market. The higher price of water that is likely to result from an increase in energy prices may actually lead to an increase in the economic surplus from water use-the area between both curves. The higher price of output may more than compensate for the increase in energy costs. This is likely to occur in regions with low transportation costs and with smaller increases in marginal energy requirements as water use increases. 


\subsection{Future and environmental considerations}

The analysis thus far has ignored some of the future costs and environmental side effects associated with water use. Water may be a non-renewable resource. In addition, water extraction may impose environmental costs as water is diverted away from its de facto use of providing ecosystem services. At the optimum, the price of water, is equal to the total marginal cost, where the total marginal cost is the sum of the externality cost, the marginal future cost of water extracted today, reflecting the discounted, reduced benefits of water use in the future, and the marginal externality cost of water use. The higher energy price will increase extraction costs and may or may not increase marginal benefits.

In the likely case that higher energy costs reduce the gap between future marginal benefits and the sum of future extraction and environmental costs, they will reduce the future cost of water extracted today. It is not clear, a priori, how an increase in energy prices will affect marginal externality costs, but it is plausible to assume that marginal externality costs will not be affected by changes in energy prices. Thus, the difference between marginal extraction costs and the social marginal cost, which is the sum of the extraction, future, and externality costs, declines as the energy price increases. Marginal benefits may not change with higher energy prices because the food price effect is countered by the transportation and other input effect. In this case, the higher energy cost increases the socially optimal price of water and reduces the level of optimal water use. If the marginal benefit of water increases with higher energy cost because of a dominant food price effect, the social optimum results in a higher water price and higher water extraction than when the food price effect is not dominant.

In the case of an open access groundwater aquifer, the future costs will not be considered by individual users, which will lead to over-extraction. However, the distortion associated with ignoring the future costs will decline as energy costs increase and the open-access outcome may become closer to the social optimum. The environmental externalities will be completely ignored unless water providers and users are provided incentives or regulated. In many cases, the suboptimal water allocations resulting from ignorance of marginal future and marginal externality costs are trivial compared to the misallocations of water resulting from policy, such as the subsidization of water that make the price of water lower than the cost of extraction.

\subsection{Market and policy constraints}

An increase in water pricing may require adjustment to accommodate the poor. A preferable solution response to poverty is the development of a welfare payment system that offers the poor income support, but does not distort production decisions. When governments are unable to raise the funds (by taxation) to support the poor, alternative policies may be considered, such as the introduction of tiered pricing to allow access to a minimal amount of water at a low price, or the introduction of a system of transferable rights that will distribute water rights broadly (perhaps proportionally to historical use) and 
allow poorer and less-efficient farmers to gain income by selling, renting, or trading their water rights. The transition to economic water pricing will be easier if the higher energy pricing in question has significant food price effects that dominate the transportation and other input effects. The domination of food price effects will increase the income of farmers, which will make water pricing reform more feasible because of reduced demand for adjustments to address distributional considerations.

\section{Water systems with extraction, conveyance, and use}

Frequently, water extraction and use occur at different locations, and a key element of water systems is the transport of water from the source to its use in irrigation or other activities. The transfer requires construction of canals and aqueducts and sometimes investment in energy to lift water. On the other hand, frequently water moves downhill and, as it moves, it is a source of hydroelectric power. Thus, increasing energy prices may impose extra cost or provide extra earning that may affect the amount of water available and its productivity. A related issue is the maintenance and upkeep of the conveyance canals that affects conveyance losses and water allocation in terms of availability over different regions.

As was mentioned earlier, in assessing the optimal management of water systems, one must consider the benefits, the extraction costs, the future and externality costs, and another element - the conveyance net benefit. For simplicity, we will ignore the future and environmental costs by assuming water is a renewable resource with no externalities. We assume there are no transmission losses and that all of the water extracted will go through the system. Net conveyance benefit is a net energy benefit associated with the transfer of water. This function is positive when the transfer of water generates energy, and negative when it consumes energy.

If the transfer of water produces more hydroelectric power than it uses, higher energy prices will increase the demand for water and increase extraction of water. If, on the other hand, transfer of water requires energy, increases in energy price will reduce the extraction of water. There is a gap between the price of extracted water, and the price of water to the final users. The optimal price of water for the final users is the price of the extracted water minus the marginal net benefits from energy.

If there is a net gain from the production of hydroelectric power, the addition of the net conveyance benefit consideration reduces the optimal price of water to the farmer, but if there is a net energy loss it will increase the optimal price of water to the farmer. If higher energy prices have a positive effect on marginal benefits that surpasses the extra marginal cost of extraction and other marginal input costs, an increase in the price of energy may actually lead to an increase in water use in farming. If an increase in the price of energy results in a bigger increase in the marginal net benefits from transmission than the increase in the marginal extraction cost, the price of water to farmers will decline. These results suggest geography matters. Water systems where end users are downhill from the source, 
and which use water to produce hydroelectric power, may actually be expanded after energy prices increase, while water systems where end users are uphill from the source, which require energy for the conveyance of water, will decline.

\section{Biofuels and alternative energy}

The rise in energy prices in recent years reflects a growing demand spurred by high economic growth rates in Asia and physical and political constraints on the supply of fuels. The growth in energy demand is likely to continue, and it is anticipated that world energy demand will increase 70 percent in the next quarter-century. This coupled with the concern about global warming and the depletion of oil reserves has fueled a scramble for alternative fuels, and biofuels appear to be highly competitive among alternatives, especially in the shorter run. Thus, provision of crops for fuel production is likely to become an increasingly important agricultural activity. Furthermore, significant water resources will be diverted for the generation of biofuels and alternative fuels, including oils from coal, gas, tar sands, and from deep, partially depleted wells. So, assessing the impacts of increasing energy prices and scarcity on the water sector has to incorporate the growing demand for water in energy production, in addition to the changes in demand for foods and the changes in the cost of water extraction and transfer.

We will analyze the impact of biofuels within large systems that affect food prices (national or international water systems). Because the demand for food is inelastic [1], the derived demand for water for food production is inelastic and has a steeper slope than the demand for water for energy production, since the demand for energy has a relatively more elastic demand, reflecting that a small change in price may lead to a relatively large increase in quantity demanded.

As the price of energy increases, biofuels can compete with food production for the use of water. The higher marginal cost of water and the increase in demand, mostly due the introduction of biofuels, will increase the optimal price of water and the quantity of water demanded may increase, but the amount of water going to agriculture declines. This decline in the amount of water going to agriculture will reduce the production of food from irrigated agriculture and contributed to reduction of food availability, resulting in higher food prices. Lower availability of food and the resulting higher costs are likely to disproportionately affect the poor, especially in developing countries. Thus, the introduction of biofuels with the aim of providing cheaper fuel may harm the poor.

As a result of increased demand for ethanol, corn prices in 2007 are at historic highs and the stock-consumption ratio for corn is at the lowest level it has been for a long time. Unlike urban poor and the rural landless poor, higher prices for agricultural commodities can be beneficial to the landholding poor. The negative effects of biofuels on the poor can be mitigated by research that increases the productivity of conventional crops and bio-fuels.

The introduction of conservation technologies, and in particular, yieldenhancing technologies that increase the productivity of traditional crops, may 
reduce the impact of biofuels on the food sector. Specifically, given the demand for food is inelastic, introduction of technologies that will enhance yields will reduce food pricing, and most importantly, will reduce the amount of water needed for food production for a given set of water and energy prices. The downward shift in the energy (biofuel) demand for water may also shift water demand downwards, but less so than the shift in food demand for water. Thus, the net effect will be a reduction in both water use and water prices, and the lower water prices will further reduce the price of food and increase food production (relative to the case without the new technology). If the improvements in productivity are very drastic, the new technologies may even result in an outcome that increases water price (because of the increased cost of extraction) but may not increase water use relative to the initial solution before biofuels.

Since the expansion of water use for agricultural production has environmental costs, the introduction of new technologies that increase the productivity both of biofuels and of traditional food crops not only reduces the pressure on consumers, it also contributes to reduced depletion of water resources and addresses environmental problems. The analysis in this section assumes that water pricing is determined by the intersection of extraction costs and demand, and we do not consider environmental or future costs. Our analysis provides qualitative insight that fits the existing reality, but the reality is worse since water is subsidized. Continued subsidization of water as energy costs increase, along with increased demand for biofuels, may result in depletion of water resources, very high subsidy costs for government, and inefficiency. It also delays innovation for improved water-efficiency technologies. On the other hand, considering the externality and future costs would reduce the optimal level of water consumption and production of biofuels, while raising food prices for consumers.

The results suggest that policies that increase efficiency of production of biofuels and traditional crops will help to alleviate some of the pressures introduced by rising energy costs. One particular area that can make a difference is a more open-minded approach to transgenic crops. Already there are several hundred million acres grown with these crops, but pressure that is not scientifically supported to restrict the use of these technologies is crippling their growth and restricting their potential to reduce demand for water while increasing yields. The work of Graff and Zilberman [2] shows that the evolution of second generation transgenics that include new drought resistant varieties has been suffocating following the heavy registration requirements the EU introduced in 1999. The requirements serve as a practical ban on transgenic crops. Investors are not likely to invest in technologies that are excessively regulated, and the impact as energy and water become scarcer are likely to become substantial.

Investment in research and development for a new generation of biofuels can reduce the pressures on food crops and some of the inefficiencies associated with the production of biofuels from corn and traditional crops. A regulatory environment that would reduce transaction costs and provide the incentive to 
convert vehicles and transportation infrastructure in a way that would allow for a smooth transition to biofuels would also increase investment in the technology and in it efficient utilization.

Improved technologies both for traditional crops, pumping and biofuels would not be a complete solution to the pressures imposed on water systems by high energy costs. Incentives to reduce demand for energy that take into account the environmental costs of various energy forms and provide incentives to introduce more fuel efficient vehicles, alternative modes of transportation, and better management of energy and fuels will likely reduce the demand for biofuels crops and water for biofuels, which would help to alleviate the pressure on water systems. At the same time, increased pressure on water systems because of high energy demand may lead to a new round of investment in water projects and transfer of water from water-abundant pristine ecosystems to water-scarce regions, costing resources and causing significant environmental problems.

\section{Conclusion}

As we have considered here, rising energy prices will affect water use in a variety of ways. Higher energy prices will make the extraction and conveyance of water more costly and may produce increased demand for hydroelectric energy. High energy prices and political considerations are producing greater demand for alternative fuels, including biofuels, which are both land and water intensive. Food prices have increased and are expected to continue increasing because of the land and water supplies diverted to biofuels and because food production becomes more costly with higher energy prices. These trends will alter the allocation of water and may induce distributional problems for poor and dry regions of the world. The development of technologies to more cheaply extract water and more efficiently transport water can offset the effects of rising energy prices, which are expected to induce adoption of new and better technologies. In addition, technologies that improve agricultural productivity can mitigate the demand effects stemming from the new energy paradigm. Efficient water allocation mechanisms will become increasingly important. The results suggest that higher energy prices increase the cost of flawed institutions and of flawed distributional policies. Water rights that limit trading result in insufficient investment in modern irrigation technologies and overproduction of waterintensive crops. The cost of such inefficiencies is likely to increase as the price of energy increases, except for the case of water systems that are integrated with expandable hydroelectric power production. The literature on water reform suggests that the transition from systems of water rights to water trading is costly, and the gain from reform increases when water is scarcer. Increased energy prices will likely encourage such transitions.

Economic models can be used to determine the effects of rising energy prices on inputs, outputs, allocation decisions, and distributional impacts. This analysis suggests that the development and optimal utilization of a variety of technologies will be important as energy becomes increasingly costly. Public sector research will be important in driving innovation and the fruits of research should be 
developed, marketed and rapidly diffused without hindrance by political speculation.

\section{References}

[1] Gardner, B. The Economics of Agricultural Policies. Macmillan, New York, 1988.

[2] Graff, G.D., and D. Zilberman. "Explaining Europe's Resistance to Agricultural Biotechnology.” ARE Update 7:5 (May/June 2004). 